\title{
Verificação da Adequação do Conteúdo Textual dos Serviços Web Públicos Brasileiros para Usuários com Baixo Letramento
}

\author{
Alternative Title: Verification of the Textual Content \\ Adequacy of Brazilian Public Web Services for Low \\ Literacy Users
}

\author{
Eliane Pinheiro Capra \\ Departamento de Informática \\ Aplicada, Universidade Federal do \\ Estado do Rio de Janeiro \\ Av. Pasteur 458 - Urca, Rio de \\ Janeiro, Brasil \\ +55 $212530-8051$ \\ eliane.capra@uniriotec.br
}

\author{
Simone Bacellar Leal Ferreira \\ Departamento de Informática \\ Aplicada, Universidade Federal do \\ Estado do Rio de Janeiro \\ Av. Pasteur 458 - Urca, Rio de \\ Janeiro, Brasil \\ +55 21 2530-8051 \\ simone@uniriotec.br
}

\author{
Bruno Augusto Torres \\ Departamento de Informática \\ Aplicada, Universidade Federal do \\ Estado do Rio de Janeiro \\ Av. Pasteur 458 - Urca, Rio de \\ Janeiro, Brasil \\ +55 21 2530-8051 \\ bruno.augusto@uniriotec.br
}

\begin{abstract}
RESUMO
A popularização da internet propiciou o acesso a diferentes sistemas por meio de diferentes dispositivos. No Brasil, há anos tem se investido no acesso aos portais das instituições públicas, visando garantir o acesso por diferentes grupos de usuários, como os analfabetos funcionais. O presente artigo tem como objetivo verificar a adequação do conteúdo informacional dos serviços disponibilizados nos portais de instituições públicas para analfabetos funcionais, de forma a identificar possíveis melhorias no acesso à informação, com apoio de uma ferramenta de análise textual. Para isso, foram analisados textos de 26 serviços web disponíveis num portal público com uma ferramenta que avalia a coesão, coerência e dificuldade dos textos, além da aplicação de uma fórmula de inteligibilidade. Os resultados mostraram que todos os serviços avaliados não estão acessíveis para analfabetos funcionais.
\end{abstract}

\section{Palavras-Chave}

Acessibilidade; Inteligibilidade; Analfabetismo Funcional;

\footnotetext{
ABSTRACT

The internet popularization provided access to different systems through different devices. In Brazil, access to the public institutions portals has been invested for years in order to guarantee access by different users groups, such as functional illiterates. This article aims to verify the adequacy of the informational content of the services provided in the portals of public institutions for functional illiterates, in order to identify

Permission to make digital or hard copies of all or part of this work for personal or classroom use is granted without fee provided that copies are not made or distributed for profit or commercial advantage and that copies bear this notice and the full citation on the first page. To copy otherwise, or republish, to post on servers or to redistribute to lists, requires prior specific permission and/or a fee.

SBSI 2017, June $5^{\text {th }}-8^{\text {th }}, 2017$, Lavras, Minas Gerais, Brazil.

Copyright SBC 2017.
}

possible improvements in access to information, with the support of a textual analysis tool. For this, we analyzed 26 web texts of services available in a public portal with a tool that evaluates the cohesion, coherence and difficulty of the texts, besides the application of a formula of intelligibility. The results showed that all services evaluated are not accessible to functional illiterates.

\section{CCS Concepts}

- Human-centered computing Accessibility

\section{Keywords}

Accessibility; Intelligibility; Functional Illiteracy;

\section{INTRODUÇÃO}

Com a popularização da internet, a Tecnologia da Informação tem feito cada vez mais parte da vida das pessoas, proporcionando o acesso por meio de diferentes dispositivos à diferentes sistemas [17].

No Brasil, há mais de 10 anos, o Governo tem investido no acesso das pessoas com diferentes necessidades ou limitações ao conteúdo informacional de seus portais disponibilizando informações e serviços web [3]. Mas para que as pessoas tenham acesso ao conteúdo desses portais, não podem existir barreiras que impeçam seu uso [7].

Como forma de conscientizar e promover a inclusão digital das pessoas, algumas leis foram definidas, como: Lei 10.098 que estabelece critérios para promover a acessibilidade das pessoas deficientes ou com limitações [4]; Lei 12.965, que estabelece critérios para o uso da internet no Brasil [5]; e Lei 13.146 que institui a inclusão das pessoas com deficiência visando sua inclusão social [6].

Entretanto, mesmo com essas leis em vigor, existem barreiras que impedem o acesso das pessoas com deficiência ou limitação ao conteúdo informacional disponível na internet. Essas barreiras 
podem afetar, principalmente, as pessoas com baixo letramento, chamadas analfabetas funcionais. Algumas pesquisas, baseadas em avaliações com pessoas com baixo letramento, mostraram que o conteúdo textual de alguns portais do Governo não estava adequado para a compreensão deste grupo de usuários [2], [7].

Logo, é essencial evitar que o baixo letramento se torne um obstáculo para o acesso dos analfabetos funcionais aos serviços disponíveis em sites do Governo Brasileiro, pelo fato de serem frequentemente desenvolvido e organizado por pessoas letradas e habituadas com o universo digital [16].

A presente pesquisa, de caráter exploratório, tem como objetivo verificar a adequação das informações textuais para cidadãos com baixo letramento, com apoio de uma ferramenta automática de análise textual. Para isso, foram analisados alguns serviços web fornecidos por um Órgão Público Federal, a fim de identificar possíveis barreiras no acesso à informação para esses usuários. A verificação foi baseada nos resultados obtidos da aplicação da ferramenta Coh-Metrix-Dementia e da aplicação da fórmula Flesch Reading Ease no conteúdo textual de 26 serviços disponíveis no portal da Secretaria da Previdência Social.

Este artigo foi dividido da seguinte maneira: a seção 2 apresenta um levantamento sobre acessibilidade web e inteligibilidade; a seção 3 elenca, sucintamente, dois trabalhos relacionados ao tema do artigo; a seção 4 discorre sobre o método de pesquisa ao qual se baseou o estudo; a seção 5 descreve os objetos selecionados para a pesquisa; a seção 6 apresenta como foi realizado o levantamento dos dados do conteúdo textual dos objetos selecionados e os resultados objetivos; a seção 7 descreve a análise dos resultados; a seção 8 apresenta a conclusão da pesquisa.

\section{ANALFABETISMO FUNCIONAL}

Os analfabetos funcionais são pessoas que possuem dificuldades nas habilidades de leitura, escrita, cálculos e ciências [1]. Essas dificuldades podem afetar até pessoas com ensino superior completo [12] [18]. Algumas instituições baseiam-se na escolaridade para classificar uma pessoa como analfabeta funcional, como o Instituto Nacional de Estudos e Pesquisas Educacionais Anísio Teixeira (INEP) e o Instituto Brasileiro de Geografia e Estatística (IBGE). Desta forma, são consideradas analfabetas funcionais aquelas com escolaridade inferior a quatro anos completos de estudo, equivalente à antiga quarta série (ou atual quinto ano) incompleta do ensino fundamental [11].

Embora o analfabetismo funcional tenha diminuído quase 3\% nos últimos quatro anos, a quantidade de analfabetos funcionais aumentou em relação ao número absoluto [19] (mais ou menos 1,5 milhões de pessoas a mais), tendo em vista o crescimento da população nas últimas décadas. Hoje, estima-se que no Brasil existam mais de 24 milhões de analfabetos funcionais.

Com o crescimento do uso da internet, esse público tem livre acesso e tem conquistado seu espaço nos serviços oferecidos na web. Atualmente, no Brasil, 26\% dos analfabetos funcionais que acessam a internet, buscam informações sobre produtos e serviços na web [8].

\subsection{Inteligibilidade}

Existem diversos aspectos envolvidos para compreender a leitura de um texto, organizados em três grandes grupos: o texto, o leitor e a intervenção pedagógica [1] [14] [21]. A presente pesquisa focou apenas no grupo "texto".

Dentre os fatores relacionados ao grupo texto destacam-se a legibilidade e a inteligibilidade. A legibilidade diz respeito à apresentação gráfica do texto [14] [21], ou seja, à possibilidade de reconhecer letras e palavras [1]. A inteligibilidade é diferente de legibilidade, pois está relacionada a quão facilmente um texto pode ser lido e compreendido [1] [21].

Assim, a inteligibilidade, como um conceito mais abrangente, refere-se a todos os fatores que afetam o sucesso da compreensão de um texto [1]. No âmbito da web, a inteligibilidade está relacionada à adequação dos conteúdos escritos ao perfil cultural, linguístico e educacional de cada pessoa [16].

Pesquisas revelaram que um texto escrito com sentenças longas e complexas, com diversos níveis de subordinação e a utilização de palavras de baixa frequência dificultam a inteligibilidade, aumentando o grau de dificuldade para compreensão de um texto para alguns grupos de pessoas, como os analfabetos funcionais [1] [20] [21].

Neste contexto de inteligibilidade, uma pesquisa comparou o desempenho da navegação em sites de busca de pessoas com baixa escolaridade com usuários alfabetizados. Esta pesquisa revelou que usuários com baixo letramento levam oito vezes mais tempo para realizar uma tarefa e gastam, em média, um terço a mais na navegação dentro de uma página do que usuários alfabetizados [13].

\section{TRABALHOS RELACIONADOS}

Para a presente pesquisa, foram selecionados alguns trabalhos disponíveis na literatura que realizaram análises textuais em conteúdos informativos para diferentes contextos, descritos nas próximas seções.

\subsection{Análise da Inteligibilidade de Textos via Ferramentas de Processamento de Língua Natural: Adaptando as Métricas do Coh- Metrix para o Português}

O artigo de Scarton e Aluísio [21] teve como objetivo adaptar as métricas Coh-Metrix do inglês para a língua Portuguesa, dando origem à ferramenta Coh-Metrix-Port, capaz de avaliar a coesão, coerência e a dificuldade de um texto.

O trabalho aplicou a ferramenta de forma a avaliar textos jornalísticos em seu formato original (complexo) e adaptado (simples). Dentre as métricas do Coh-Metrix-Port, oito foram utilizadas na avaliação dos textos: número de palavras, número de sentenças, frequências de palavras de conteúdo, mínimo de frequências de palavras de conteúdo, palavras antes de verbo principal, número de pronomes, quantidade de pronomes por sintagmas, número de operadores ("e", "ou", "se" e negações). Além dessas métricas, a fórmula Flesch Reading Ease também foi utilizada.

\subsection{Coh-Metrix-Dementia: Análise Automática de Distúrbios de Linguagem nas Demências Utilizando Processamento de Línguas Naturais}

Esse trabalho, desenvolvido em 2015 [10], teve como objetivo disponibilizar um ambiente unificado computacional de forma a 
possibilitar a análise e reconhecimento automatizado de comprometimentos cognitivos, como as demências. Como resultado foi o desenvolvimento do Coh-Metrix-Dementia, que conta com as mesmas métricas do Coh-Metrix-Port, sendo que soma mais 25 métricas capazes de classificar as narrativas de pessoas normais, pessoas com doença de Alzheimer e comprometimento cognitivo leve.

\section{MÉTODO DE PESQUISA}

O presente trabalho, de caráter qualitativo e exploratório, seguiu quatro etapas, descritas a seguir:

1) Seleção dos objetos de pesquisa: após o levantamento bibliográfico, realizou-se a seleção dos serviços que oferecessem informações úteis para o público alvo dessa pesquisa. Optou-se por aqueles que oferecessem informações básicas para a população brasileira. Foram selecionados os 26 serviços web disponíveis no Portal da Secretaria da Previdência Social [22].

2) Definição das métricas: foi necessário definir as métricas usadas para verificar a adequação do conteúdo textual para o público escolhido. Foram selecionadas oito métricas dentre as 59 disponíveis na ferramenta Coh-Metrix-Dementia [9]. A seleção baseou-se no trabalho de Scarton e Aluísio [21], apresentado na seção 3.1. Além das métricas, também foi extraído o resultado da aplicação da fórmula Flesch Reading Ease, por ser uma das mais populares no Brasil [2]. Esta fórmula identifica o grau de dificuldade de um texto, classificando-o em: muito difícil (0-25), difícil (25-50), fácil (50-75) e muito fácil (75-100, ideal para pessoas com baixo letramento) [21].

3) Levantamento dos dados do conteúdo textual: essa etapa consistiu na cópia de todo conteúdo textual informacional de cada um dos serviços em um arquivo texto, desconsiderando os botões disponíveis no meio desses textos. Depois, esse conteúdo foi movido para a ferramenta Coh-Metrix-Dementia para avaliar a coesão, coerência e dificuldade dos textos analisados. Cada serviço teve seu conteúdo textual avaliado individualmente pela ferramenta.

4) Análise dos resultados obtidos: após a verificação do conteúdo, os dados foram tabulados e analisados baseando-se nas oito métricas do Coh-Metrix-Dementia e da Fórmula Flesch Reading Ease. A ferramenta Coh-Metrix-Dementia gera os resultados calculando incidência para cada métrica apurada. Para melhor entendimento, os autores converteram alguns resultados em números quantitativos e percentuais. Essa etapa está descrita na seção 7.

\section{SELEÇÃO DOS OBJETOS DE PESQUISA}

\subsection{Seleção dos Serviços Oferecidos aos Cidadãos}

Foi necessário selecionar serviços online cuja as informações textuais pudessem ser acessadas por qualquer cidadão. Optou-se pelos serviços do Portal da Secretaria da Previdência Social [22], pois todo conteúdo segue as diretrizes do Modelo de Acessibilidade do Governo Eletrônico (e-MAG) e dos Padrões $W e b$ em Governo Eletrônico, além de oferecer navegação por teclado e teclas de atalho [23]. A Tabela 1 apresenta os 26 serviços selecionados [22].
Tabela 1. Serviços disponíveis no Portal da Secretaria da Previdência Social [22]

\begin{tabular}{|c|l|}
\hline Numeração & \multicolumn{1}{|c|}{ Serviço } \\
\hline 1 & Agendamento \\
\hline 2 & Atualização de cadastro e senha \\
\hline 3 & Atualização de tempo de contribuição \\
\hline 4 & Atualizção de Endereço de Beneficiário \\
\hline 5 & Cadastramento de Declaração de Cárcere \\
\hline 6 & Cálculo da Guia da Previdência Social (GPS) \\
\hline 7 & Carta de Concessão e Memória de Cálculo \\
\hline 8 & Certidão de Tempo de Contribuição - CTC \\
\hline 9 & Certidão para Saque do PIS/PASEP/FGTS \\
\hline 10 & Comunicação de Acidente de Trabalho - CAT \\
\hline 11 & Consulta de Perícias Médicas Agendadas \\
\hline 12 & Consulta de situação de benefício \\
\hline 13 & Cópia/Vista/Carga de processo administrativo \\
\hline 14 & Débito Automático de GPS em Conta Corrente \\
\hline 15 & $\begin{array}{l}\text { Declaração de Regularidade da Situação do } \\
\text { Contribuinte Individual - DRSCI }\end{array}$ \\
\hline 16 & Demonstrativo de Imposto de Renda \\
\hline 17 & Empréstimo consignado \\
\hline 18 & Extrato de contribuições à Previdência Social \\
\hline 19 & Extrato de pagamento de benefício \\
\hline 20 & $\begin{array}{l}\text { Inclusão ou alteração de conta bancária para } \\
\text { pagamento de benefícios }\end{array}$ \\
\hline 21 & Inscrição na Previdência Social \\
\hline 22 & Prova de vida e renovação de senha bancária \\
\hline 23 & Recurso \\
\hline 26 & Revisão de benefício \\
\hline Simulação \\
\hline Transferência de Benefício em Manutenção - \\
\hline TBM \\
\hline
\end{tabular}

Cabe destacar que, na página principal dos Serviços, é apresentado um ranking dos serviços mais procurados pelo cidadão [22], são eles: (1) Agendamento, (6) Cálculo de Guia da Previdência Social, (12) Consulta de Situação de Benefício, (7) Carta de Concessão, (19) Extrato de Pagamento de Benefício e (25) Simulação.

\section{LEVANTAMENTO DOS DADOS DO CONTEÚDO TEXTUAL}

\subsection{Preparação dos Textos}

Esta etapa consistiu na cópia dos conteúdos informativos de cada serviço para um documento texto. Neste documento, foram eliminadas as linhas em branco e alguns caracteres que o sistema Coh-Metrix-Dementia não processa, como: (a) símbolo de grau "o"; e (b) sinais de pontuação em locais dentro do texto que o sistema entende como não sendo adequada a sua colocação.

Esta "limpeza" nos textos foi necessária para que ferramenta não apresentasse mensagem de erro.

\subsection{Resultados Obtidos da Ferramenta Coh- Metrix-Dementia}

Após a preparação, cada texto foi copiado para dois campos textuais do Coh-Metrix-Dementia e submetidos para análise da 
ferramenta. Depois da execução, os dados gerados pelo sistema foram baixados no formato .json.

Foi criado um arquivo .json por serviço. As informações contidas nesses arquivos foram importadas para uma planilha para melhor análise dos dados. Após a importação e a conversão em números, foi criada a Tabela 2 com os resultados obtidos da análise das oito métricas selecionadas.

Tabela 2. Dados Coletados com a Ferramenta Coh-Metrix-Dementia

\begin{tabular}{|c|c|c|c|c|c|c|c|c|c|c|c|c|c|}
\hline Serviços do Portal & 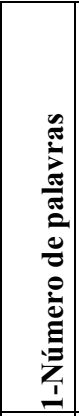 & 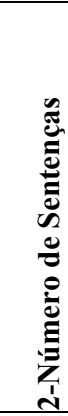 & 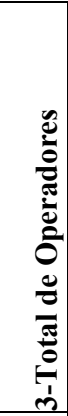 & 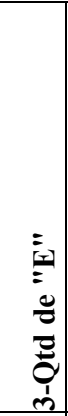 & 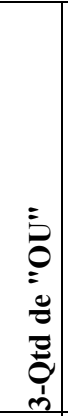 & 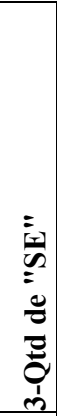 & 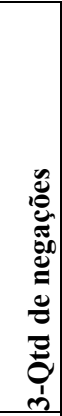 & 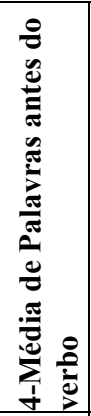 & 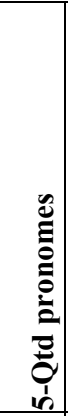 & 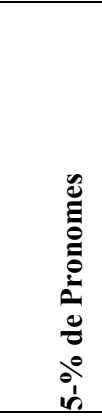 & 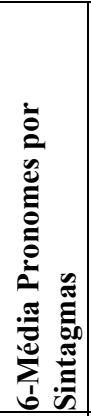 & 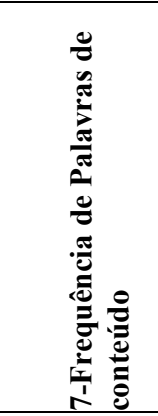 & 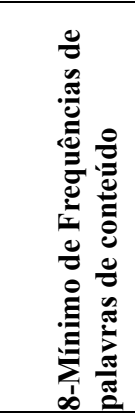 \\
\hline Agendamento & 157 & 13 & 5 & 4 & 0 & 0 & 1 & 2,23 & 15 & $9,60 \%$ & 0,02 & 521823,78 & 18785 \\
\hline Atualização de cadastro e senha & 256 & 22 & 9 & 6 & 2 & 0 & 1 & 1,45 & 13 & $5,10 \%$ & 0,00 & 642189,9 & 14753,27 \\
\hline $\begin{array}{l}\text { Atualização de endereço de } \\
\text { beneficiário }\end{array}$ & 72 & 7 & 2 & 1 & 1 & 0 & 0 & 2,00 & 4 & $5,60 \%$ & 0,01 & 818669,26 & 7813,86 \\
\hline $\begin{array}{l}\text { Atualização de tempo de } \\
\text { contribuição }\end{array}$ & 213 & 14 & 7 & 4 & 2 & 0 & 1 & 3,57 & 9 & $4,20 \%$ & 0,00 & 799619,93 & 8250,57 \\
\hline $\begin{array}{l}\text { Cadastramento de Declaração de } \\
\text { Cárcere }\end{array}$ & 286 & 20 & 11 & 2 & 4 & 1 & 4 & 4,70 & 14 & $4,90 \%$ & 0,00 & 755090,9 & 15002,5 \\
\hline $\begin{array}{l}\text { Cálculo da Guia da Previdência } \\
\text { Social - GPS }\end{array}$ & 425 & 31 & 14 & 9 & 4 & 1 & 0 & 2,77 & 15 & $3,50 \%$ & 0,01 & 665040,69 & 5351,81 \\
\hline $\begin{array}{l}\text { Carta de concessão e memória de } \\
\text { cálculo }\end{array}$ & 105 & 7 & 3 & 2 & 0 & 1 & 0 & 2,86 & 5 & $4,80 \%$ & 0,01 & 672161,68 & 11102,43 \\
\hline $\begin{array}{l}\text { Certidão de tempo de contribuição } \\
\text { (CTC) }\end{array}$ & 423 & 26 & 17 & 8 & 3 & 1 & 5 & 2,35 & 22 & $5,20 \%$ & 0,00 & 933166,21 & 12856,27 \\
\hline $\begin{array}{l}\text { Certidão para Saque do } \\
\text { PIS/PASEP/FGTS }\end{array}$ & 150 & 14 & 4 & 2 & 1 & 1 & 0 & 1,71 & 10 & $6,70 \%$ & 0,00 & 478402,76 & 23454,36 \\
\hline $\begin{array}{l}\text { Comunicação de Acidente de } \\
\text { Trabalho - CAT }\end{array}$ & 738 & 43 & 43 & 16 & 18 & 1 & 8 & 5,42 & 21 & $2,80 \%$ & 0,00 & 746707,9 & 23969,09 \\
\hline $\begin{array}{l}\text { Consulta de perícia médica } \\
\text { agendada }\end{array}$ & 93 & 10 & 3 & 3 & 0 & 0 & 0 & 2,10 & 7 & $7,50 \%$ & 0,00 & 672956,95 & 41405,1 \\
\hline Consulta de situação de benefício & 66 & 6 & 1 & 1 & 0 & 0 & 0 & 2,00 & 2 & $3,00 \%$ & 0,01 & 887114,26 & 12237,83 \\
\hline $\begin{array}{l}\text { Cópia/Vista/Carga de processo } \\
\text { administrativo }\end{array}$ & 257 & 17 & 8 & 3 & 3 & 1 & 1 & 4,18 & 14 & $5,40 \%$ & 0,00 & 583088,31 & 16168,53 \\
\hline $\begin{array}{l}\text { Débito Automático de GPS em } \\
\text { Conta Corrente }\end{array}$ & 249 & 24 & 5 & 4 & 1 & 0 & 0 & 1,83 & 7 & $2,80 \%$ & 0,01 & 1032991,5 & 2653,75 \\
\hline $\begin{array}{l}\text { Declaração de regularidade da } \\
\text { situação do contribuinte individual } \\
\text { (DRSCI) }\end{array}$ & 520 & 30 & 25 & 8 & 4 & 8 & 5 & 6,77 & 13 & $2,50 \%$ & 0,00 & 379075,72 & 8567,83 \\
\hline Demonstrativo de Imposto de Renda & 73 & 6 & 1 & 1 & 0 & 0 & 0 & 3,00 & 1 & $1,40 \%$ & 0,02 & 3493553,8 & 9008,33 \\
\hline Empréstimo consignado & 858 & 39 & 44 & 15 & 19 & 0 & 10 & 4,56 & 32 & $3,70 \%$ & 0,00 & 448819,29 & 7351,74 \\
\hline Extrato de pagamento de benefício & 97 & 7 & 3 & 3 & 0 & 0 & 0 & 3,29 & 5 & $5,20 \%$ & 0,02 & 1160943,2 & 2739,14 \\
\hline $\begin{array}{l}\text { Extrato de vínculos e contribuições } \\
\text { à Previdência }\end{array}$ & 201 & 13 & 12 & 8 & 2 & 0 & 2 & 4,15 & 8 & $4,00 \%$ & 0,01 & 876373,2 & 8152,08 \\
\hline $\begin{array}{l}\text { Inclusão ou alteração de conta } \\
\text { bancária }\end{array}$ & 376 & 27 & 16 & 5 & 7 & 1 & 3 & 3,67 & 20 & $5,30 \%$ & 0,00 & 316269,08 & 15117,85 \\
\hline
\end{tabular}




\begin{tabular}{|c|c|c|c|c|c|c|c|c|c|c|c|c|c|}
\hline Serviços do Portal & 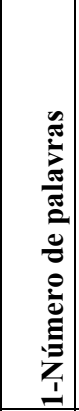 & 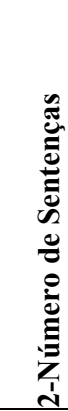 & 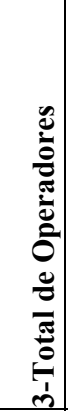 & 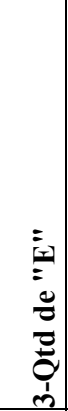 & $\begin{array}{l}\vdots \\
0 \\
0 \\
0 \\
0 \\
0 \\
0 \\
0 \\
0 \\
m \\
m\end{array}$ & 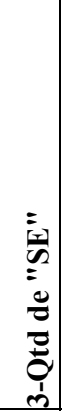 & 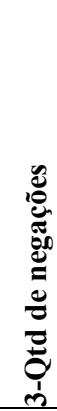 & 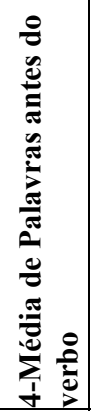 & 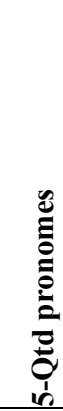 & 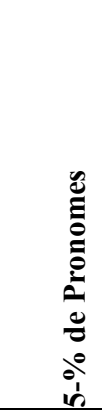 & 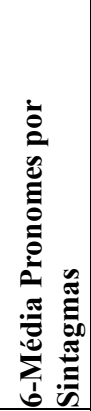 & 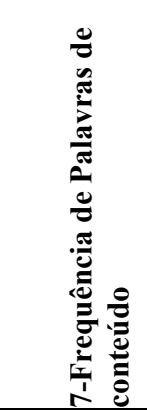 & 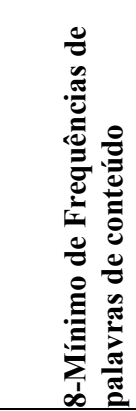 \\
\hline Inscrição na Previdência Social & 459 & 37 & 23 & 6 & 7 & 3 & 7 & 3,27 & 26 & $5,70 \%$ & 0,00 & 711975,83 & 12656,16 \\
\hline $\begin{array}{l}\text { Prova de vida e renovação da senha } \\
\text { bancária }\end{array}$ & 590 & 37 & 23 & 11 & 4 & 1 & 7 & 5,70 & 37 & $6,30 \%$ & 0,00 & 696137,9 & 16634,22 \\
\hline Recurso & 429 & 32 & 12 & 7 & 1 & 0 & 4 & 3,03 & 33 & $7,70 \%$ & 0,00 & 1027288,4 & 10826125 \\
\hline Revisão & 366 & 26 & 13 & 6 & 6 & 0 & 1 & 2,08 & 21 & $5,70 \%$ & 0,00 & 582902,21 & 20402,96 \\
\hline Simulação & 213 & 15 & 9 & 3 & 0 & 1 & 5 & 3,53 & 19 & $8,90 \%$ & 0,02 & 548076,98 & 16164,33 \\
\hline Transferência de benefício & 345 & 20 & 12 & 7 & 4 & 0 & 1 & 2,55 & 29 & $8,40 \%$ & 0,00 & 532181,67 & 9120,25 \\
\hline
\end{tabular}

Além da coleta dos dados para análise das métricas, também foram extraídos os resultados da aplicação da Fórmula Flesh Reading Ease sobre os textos analisados, conforme Tabela 3. Com esses resultados, foi possível inferir o grau de dificuldade e a série escolar necessária para compreender o conteúdo textual.

Tabela 3. Complexidade do Texto Baseado na Fórmula Flesh

\begin{tabular}{|c|c|c|c|}
\hline Serviços do Portal & $\begin{array}{c}\text { Flesh } \\
\text { Reading } \\
\text { Ease }\end{array}$ & $\begin{array}{c}\text { Grau de } \\
\text { Dificuldade }\end{array}$ & $\begin{array}{l}\text { Série da } \\
\text { Educação }\end{array}$ \\
\hline Agendamento & 25,89 & DIFÍCIL & $\begin{array}{l}9^{\circ} \text { ANO E } \\
2^{\circ} \text { GRAU }\end{array}$ \\
\hline $\begin{array}{l}\text { Atualização de } \\
\text { cadastro e senha }\end{array}$ & 31,14 & DIFÍCIL & $\begin{array}{l}9^{\circ} \mathrm{ANO} \text { E } \\
2^{\circ} \mathrm{GRAU}\end{array}$ \\
\hline $\begin{array}{c}\text { Atualização de } \\
\text { endereço de } \\
\text { beneficiário }\end{array}$ & 32,77 & DIFÍCIL & $\begin{array}{l}9^{\circ} \mathrm{ANO} \text { E } \\
2^{\circ} \mathrm{GRAU}\end{array}$ \\
\hline $\begin{array}{c}\text { Atualização de } \\
\text { tempo de } \\
\text { contribuição }\end{array}$ & 27,65 & DIFÍCIL & $\begin{array}{l}9^{\circ} \mathrm{ANO} E \\
2^{\circ} \mathrm{GRAU}\end{array}$ \\
\hline $\begin{array}{l}\text { Cadastramento de } \\
\text { Declaração de } \\
\text { Cárcere }\end{array}$ & 31,40 & DIFÍCIL & $\begin{array}{l}9^{\circ} \text { ANO E } \\
2^{\circ} \text { GRAU }\end{array}$ \\
\hline $\begin{array}{l}\text { Cálculo da Guia da } \\
\text { Previdência Social } \\
\text { - GPS }\end{array}$ & 29,69 & DIFÍCIL & $\begin{array}{l}9^{\circ} \text { ANO E } \\
2^{\circ} \text { GRAU }\end{array}$ \\
\hline $\begin{array}{c}\text { Carta de concessão } \\
\text { e memória de } \\
\text { cálculo }\end{array}$ & 48,30 & DIFÍCIL & $\begin{array}{l}9^{\circ} \text { ANO E } \\
2^{\circ} \text { GRAU }\end{array}$ \\
\hline $\begin{array}{l}\text { Certidão de tempo } \\
\text { de contribuição } \\
\text { (CTC) }\end{array}$ & 37,52 & DIFÍCIL & $\begin{array}{l}9^{\circ} \text { ANO E } \\
2^{\circ} \text { GRAU }\end{array}$ \\
\hline $\begin{array}{c}\text { Certidão para } \\
\text { Saque do } \\
\text { PIS/PASEP/FGTS }\end{array}$ & 45,07 & DIFÍCIL & $\begin{array}{l}9^{\circ} \text { ANO E } \\
2^{\circ} \text { GRAU }\end{array}$ \\
\hline $\begin{array}{l}\text { Comunicação de } \\
\text { Acidente de } \\
\text { Trabalho - CAT }\end{array}$ & 33,67 & DIFÍCIL & $\begin{array}{l}9^{\circ} \mathrm{ANO} \text { E } \\
2^{\circ} \mathrm{GRAU}\end{array}$ \\
\hline $\begin{array}{l}\text { Consulta de perícia } \\
\text { médica agendada }\end{array}$ & 46,54 & DIFÍCIL & $\begin{array}{l}9^{\circ} \mathrm{ANO} \text { E } \\
2^{\circ} \mathrm{GRAU}\end{array}$ \\
\hline
\end{tabular}

\begin{tabular}{|c|c|c|c|}
\hline Serviços do Portal & $\begin{array}{c}\text { Flesh } \\
\text { Reading } \\
\text { Ease }\end{array}$ & $\begin{array}{c}\text { Grau de } \\
\text { Dificuldade }\end{array}$ & $\begin{array}{c}\text { Série da } \\
\text { Educação }\end{array}$ \\
\hline $\begin{array}{l}\text { Consulta de } \\
\text { situação de } \\
\text { benefício }\end{array}$ & 37,71 & DIFÍCIL & $\begin{array}{l}9^{\circ} \mathrm{ANO} \text { E } \\
2^{\circ} \mathrm{GRAU}\end{array}$ \\
\hline $\begin{array}{c}\text { Cópia/Vista/Carga } \\
\text { de processo } \\
\text { administrativo }\end{array}$ & 40,26 & DIFÍCIL & $\begin{array}{l}9^{\circ} \text { ANO E } \\
2^{\circ} \text { GRAU }\end{array}$ \\
\hline $\begin{array}{c}\text { Débito Automático } \\
\text { de GPS em Conta } \\
\text { Corrente }\end{array}$ & 53,14 & FÁCIL & $\begin{array}{c}5^{\circ} \mathrm{AO} 8^{\circ} \\
\mathrm{ANO}\end{array}$ \\
\hline $\begin{array}{l}\text { Declaração de } \\
\text { regularidade da } \\
\text { situação do } \\
\text { contribuinte } \\
\text { individual } \\
\text { (DRSCI) }\end{array}$ & 24,62 & $\begin{array}{l}\text { MUITO } \\
\text { DIFÍCIL }\end{array}$ & $\begin{array}{c}\text { ENSINO } \\
\text { SUPERIOR }\end{array}$ \\
\hline $\begin{array}{l}\text { Demonstrativo de } \\
\text { Imposto de Renda }\end{array}$ & 45,27 & DIFÍCIL & $\begin{array}{l}9^{\circ} \text { ANO E } \\
2^{\circ} \text { GRAU }\end{array}$ \\
\hline $\begin{array}{l}\text { Empréstimo } \\
\text { consignado }\end{array}$ & 27,13 & DIFÍCIL & $\begin{array}{l}9^{\circ} \text { ANO E } \\
2^{\circ} \text { GRAU }\end{array}$ \\
\hline $\begin{array}{c}\text { Extrato de } \\
\text { pagamento de } \\
\text { benefício }\end{array}$ & 26,32 & DIFÍCIL & $\begin{array}{l}9^{\circ} \text { ANO E } \\
2^{\circ} \text { GRAU }\end{array}$ \\
\hline $\begin{array}{l}\text { Extrato de vínculos } \\
\text { e contribuições à } \\
\text { Previdência }\end{array}$ & 33,64 & DIFÍCIL & $\begin{array}{l}9^{\circ} \text { ANO E } \\
2^{\circ} \text { GRAU }\end{array}$ \\
\hline $\begin{array}{c}\text { Inclusão ou } \\
\text { alteração de conta } \\
\text { bancária }\end{array}$ & 36,48 & DIFÍCIL & $\begin{array}{l}9^{\circ} \text { ANO E } \\
2^{\circ} \text { GRAU }\end{array}$ \\
\hline $\begin{array}{c}\text { Inscrição na } \\
\text { Previdência Social }\end{array}$ & 33,31 & DIFÍCIL & $\begin{array}{l}9^{\circ} \text { ANO E } \\
2^{\circ} \text { GRAU }\end{array}$ \\
\hline $\begin{array}{c}\text { Prova de vida e } \\
\text { renovação da senha } \\
\text { bancária }\end{array}$ & 39,22 & DIFÍCIL & $\begin{array}{l}9^{\circ} \text { ANO E } \\
2^{\circ} \text { GRAU }\end{array}$ \\
\hline Recurso & 40,19 & DIFÍCIL & $\begin{array}{l}9^{\circ} \text { ANO E } \\
2^{\circ} \text { GRAU }\end{array}$ \\
\hline Revisão & 40,15 & DIFÍCIL & $\begin{array}{l}9^{\circ} \text { ANO E } \\
2^{\circ} \text { GRAU }\end{array}$ \\
\hline
\end{tabular}


XIII Brazilian Symposium on Information Systems, Lavras, Minas Gerais, June 5-8, 2017

\begin{tabular}{|c|c|c|c|}
\hline Serviços do Portal & $\begin{array}{c}\text { Flesh } \\
\text { Reading } \\
\text { Ease }\end{array}$ & $\begin{array}{c}\text { Grau de } \\
\text { Dificuldade }\end{array}$ & $\begin{array}{c}\text { Série da } \\
\text { Educação }\end{array}$ \\
\hline Simulação & 46,16 & DIFÍCIL & $\begin{array}{c}9^{\circ} \mathrm{ANO} E \\
2^{\circ} \mathrm{GRAU}\end{array}$ \\
\hline $\begin{array}{c}\text { Transferência de } \\
\text { benefício }\end{array}$ & 28,53 & DIFÍCIL & $\begin{array}{c}9^{\circ} \mathrm{ANO} E \\
2^{\circ} \mathrm{GRAU}\end{array}$ \\
\hline
\end{tabular}

Com os dados extraídos e tabulados resultantes da aplicação da Fórmula Flesch, foram elencados os dez serviços mais críticos em relação ao grau de dificuldade de leitura, conforme Figura 1.

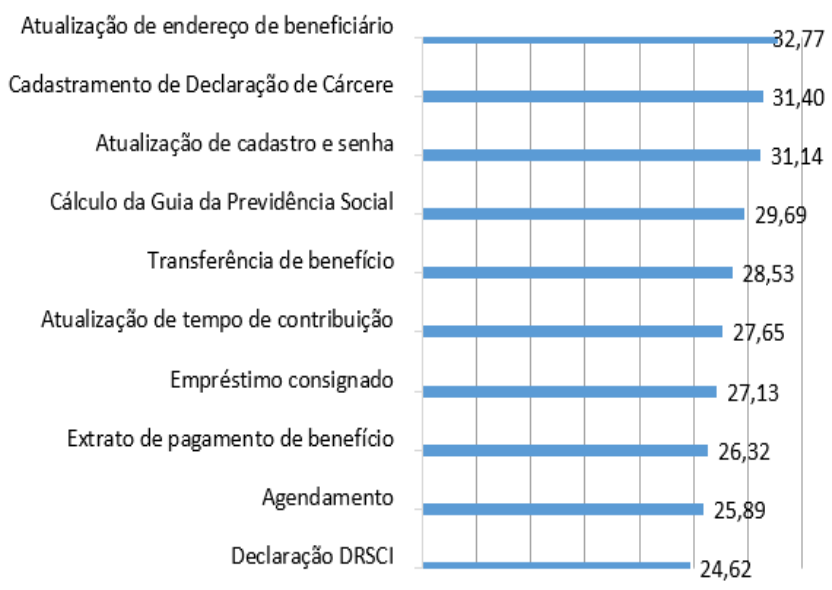

Figura 1. Dez serviços mais difíceis de ler, segundo aplicação da Fórmula Flesch

\section{ANÁLISE DOS RESULTADOS}

Tanto os pronomes como "eles/elas", quanto os pronomes por sintagmas são os principais responsáveis por dificultar a leitura [21]. Os pronomes por sintagmas dificultam ao leitor identificar a que ou quem o pronome se refere. A Tabela 2 mostra que a média de uso de pronomes pessoais é alto nos conteúdos de alguns serviços. Neste caso, os três que mais se destacam são: Agendamento (9,6\%), Simulação $(8,9 \%)$ e Transferência de benefício $(8,4 \%)$. Essa informação corrobora com o resultado da aplicação da Fórmula Flesch, onde o serviço "Agendamento" aparece como o terceiro serviço com conteúdo textual mais difícil de ser compreendido, com índice de 25,89, sendo mais adequado às pessoas com escolaridade acima do $9^{\circ}$ ano do ensino fundamental.

É importante ressaltar que "Agendamento" é um dos serviços mais procurados no Portal da Previdência, conforme apresentação na seção 5.1, e esse serviço pode não estar acessível para os $26 \%$ dos usuários analfabetos funcionais que acessam a internet em busca de informações sobre produtos e serviços [8].

Já os que menos fazem uso de pronomes são: Demonstrativo de Imposto de Renda (1,4\%), Declaração de regularidade da situação do contribuinte individual (DRSCI) (2,5\%), Débito Automático de GPS em Conta Corrente e Comunicação de Acidente de Trabalho - CAT, estes dois últimos com 2,8\%.

O uso de palavras antes do verbo também torna as sentenças mais difíceis de entender, pois sobrecarregam a memória de trabalho do leitor [21]. O serviço com a maior média de palavras antes do verbo é "Declaração de regularidade da situação do contribuinte individual (DRSCI)" com 6,77, seguido dos serviços "Prova de vida e renovação da senha bancária" $(5,70)$ e "Comunicação de Acidente de Trabalho - CAT" $(5,42)$. O primeiro serviço citado chama atenção, pois, dentre os 27 analisados, é o segundo em maior em quantidade de palavras (738) e o maior em número de sentenças (43). As informações corroboram com os resultados da aplicação da Fórmula Flesch, já que a "Declaração de regularidade da situação do contribuinte individual (DRSCI)" é o segundo serviço com conteúdo textual mais complexo, com índice de 24,62, exigindo do leitor um grau de instrução de nível superior.

O uso de partículas "e", "ou" e "se", além dos operadores de negação, também demandam elevado trabalho de memória do leitor [15]. Neste contexto, o serviço com maior média no uso de operadores por palavra é "Extrato de vínculos e contribuições à Previdência" (16,75), seguido do "Comunicação de Acidente de Trabalho - CAT" $(17,16)$ e "Empréstimo Consignado" (19,50).

Ainda nesta análise dos operadores, o serviço "Empréstimo Consignado" chama atenção, pois, embora sendo o maior serviço em número de palavras (858), esse possui 39 sentenças e 44 operadores lógicos distribuídos em: quinze "E", dezenove "OU" e dez negações; ou seja, tem-se uma média de 1,12 operador por sentença, o que o torna o pior serviço em relação ao uso de operadores. Além disso, com a aplicação da Fórmula Flesch, este serviço é o quinto mais complexo para o leitor, com um índice igual a 26,32 .

As palavras de conteúdo são aquelas mais utilizadas dentro de um texto [10]. Podem ser substantivos, adjetivos, advérbios ou verbos [10] e quanto maior o valor dessa métrica, mais inteligível é o texto [21]. O valor da métrica "frequência das palavras de conteúdo" é obtido de uma lista de frequência residente em um banco de palavras em português [10]. Os serviços que apresentaram a maior frequência no uso das palavras de conteúdo foram: Demonstrativo de Imposto de Renda (3493553,84), Extrato de Pagamento de Benefício $(1160943,15)$ e Débito Automático de GPS em Conta Corrente $(1032991,48)$.

Já a métrica "mínimo de frequência de palavras de conteúdo" avalia, sentença a sentença, as palavras mais raras utilizadas dentro do texto e quanto menor o número desta métrica, mais inteligível é o texto [21]. Neste caso, os serviços que mais se destacaram foram: Débito Automático de GPS em Conta Corrente (2653,75), Extrato de Pagamento de Benefício $(2739,14)$ e Cálculo da Guia da Previdência Social $(5351,81)$.

Considerando o uso das palavras de conteúdo, o serviço que mais se destaca é o "Débito Automático de GPS em Conta Corrente", já que apresentou melhor desempenho nas duas métricas relacionadas. Esse serviço também apresentou o terceiro melhor resultado na métrica relacionada ao uso de pronomes. Isso corrobora com o índice obtido da aplicação da Fórmula Flesch $(53,14)$, sendo de fácil leitura para usuários com grau de instrução acima do $5^{\circ}$ ano. Porém, esse serviço ainda não atinge a inteligibilidade recomendada para usuários com baixo letramento. Esse cenário também se aplica ao serviço "Extrato de Pagamento de Benefício" que, mesmo obtendo os melhores resultados dentre os serviços disponibilizados, não obteve o índice necessário de inteligibilidade com a aplicação da Fórmula Flesch (26,32 - grau de dificuldade "difícil").

Outro serviço que chama atenção nas métricas de palavras de conteúdo é o "Recurso", pois ele é o quarto com melhor desempenho na métrica "frequência das palavras de conteúdo", 
com um índice de 1027288,42 . Entretanto, apresenta o pior índice na métrica "mínimo de frequência de palavras de conteúdo" com índice de 10826125,00 (mais que o dobro do serviço com pior desempenho antes dele). Ou seja, mesmo o conteúdo textual apresentando o uso mais adequado dos substantivos, adjetivos, advérbios e verbos, este mesmo conteúdo referencia palavras não usuais, o que prejudica a leitura do usuário.

Considerando a aplicação da Fórmula Flesch sobre todos os serviços analisados (Figura 2), 100\% dos serviços analisados não possui conteúdo textual que possa ser compreendido por pessoas com baixo letramento, já que o grau mais indicado para este perfil é "Muito Fácil". O mais agravante é que, dos serviços mais procurados no Portal da Secretaria da Previdência Social, conforme apresentado na seção 5.1, todos estão com complexidade de leitura "difícill".

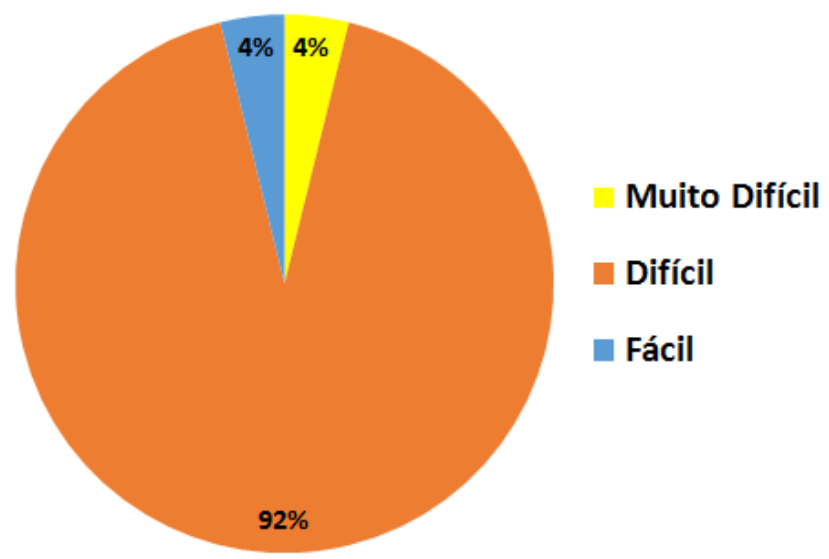

Figura 2. Complexidade Textual Baseada na Fórmula Flesch

\section{CONCLUSÃ̃}

A internet se tornou um importante meio de comunicação para troca de informações e utilização de serviços online dos Governos Federal, Estadual e Municipal. Por isso, o Governo Brasileiro tem investido na qualidade das informações disponibilizadas para a população, disponibilizando recomendações para tornar os sites acessíveis.

No contexto do analfabetismo funcional, que está relacionado à dificuldade que uma pessoa pode ter em relação as habilidades de leitura e escrita, cidadãos com esse perfil são potenciais usuários das informações oferecidas pelos portais de instituições públicas, já que tais portais oferecem diversos serviços online básicos à população.

A presente pesquisa, de caráter exploratório, teve como objetivo verificar a adequação das informações textuais dos serviços web fornecidos pelos Órgãos Públicos Federais para cidadãos com baixo letramento, a fim de identificar possíveis barreiras no acesso à informação para esses usuários. Para isso, foram selecionados 26 serviços do Portal da Secretaria da Previdência Social [22].

Todo o conteúdo textual dos serviços foi submetido à execução da ferramenta Coh-Metrix-Dementia, que avalia a dificuldade de um texto, além de identificar alguns comprometimentos cognitivos [10]. Para analisar os resultados, os autores se basearam em oito métricas utilizadas na análise do trabalho de Scarton e Aluísio [21].
Após a análise dos resultados obtidos com a execução da ferramenta, os números revelaram que o conteúdo textual de todos os serviços não estão adequados para o público com baixo letramento. $\mathrm{O}$ único serviço mais fácil de ser compreendido é o "Débito Automático de GPS em Conta Corrente", já que apresentou o melhor resultado na aplicação da Fórmula Flesch. Contudo, precisa ser reescrito para melhor ser compreendido pelos analfabetos funcionais.

Baseando-se nos resultados obtidos na aplicação da Fórmula Flesch, pode-se concluir que, apesar de existir, na Administração Pública Federal, obrigatoriedade legal do uso de diretrizes de acessibilidade, como garantir a leitura e compreensão das informações, essa recomendação não foi seguida durante a elaboração do conteúdo textual do portal analisado.

Os resultados deste trabalho corroboram com os resultados de outras pesquisas [2] [10], porém obtidos sem avaliação com humanos, baseando-se em uma análise textual de uma ferramenta online e a aplicação de uma fórmula de inteligibilidade.

Paralelamente, esses resultados podem ser considerados como o início de uma avaliação que merece ser mais aprofundada. Esperase que eles possam conscientizar desenvolvedores, especialistas e pesquisadores na adaptação e elaboração de conteúdos textuais e não textuais mais acessíveis, a fim de facilitar o acesso das pessoas com baixo letramento aos serviços básicos do Governo Brasileiro disponíveis na internet.

Como trabalho futuro, sugere-se a elaboração de uma ferramenta online para avaliação do conteúdo textual, capaz de gerar resultados básicos precisos que possibilitem auxiliar desenvolvedores e profissionais de tecnologia da informação na adaptação e elaboração de conteúdos textuais acessíveis. A criação desta ferramenta, inclusive, poderá auxiliar nas avaliações automática de acessibilidade, conforme preconiza as diretrizes de acessibilidade $w e b$ brasileiras.

\section{REFERÊNCIAS}

[1] Barboza, E. F., Nunes, E. A. 2007. A inteligibilidade dos websites governamentais brasileiros e o acesso para usuários com baixo nível de escolaridade Interação HumanoComputador. Inclusão Social, v. 2, n. 2, p.p. 19-33.

[2] Benjamin, K. M., Leal Ferreira, S. B., Cappelli, C., Capra, E. P., Silveira, D. S. 2013. Sites Governamentais: Acessíveis para Analfabetos Funcionais?. In: Encontro de Administração da Informação, 2013, Bento Gonçalves - RS. IV EnAdI.

[3] Berger, M. A. F. A 2007. Globalização da Economia, a Internet e o Ensino de Língua Inglesa como Idioma Global. Revista da Fapese, v. 3, n. 1, p.p. 35-56.

[4] Brasil. Lei 10.098. Estabelece normas gerais e critérios básicos para a promoção da acessibilidade das pessoas portadoras de deficiência ou com mobilidade reduzida, e dá outras providências, de 19 de dezembro de 2000. Brasília, DF, 2000. Disponível em:

$<$ http://www.planalto.gov.br/ccivil_03/Leis/L10098.htm> Acesso em: 20 de out. 2016.

[5] Brasil. Lei 12.965. Estabelece princípios, garantias, direitos e deveres para o uso da Internet no Brasil, de 23 de abril de 2014. Brasília, DF, 2014. Disponível em : 
$<$ http://www.planalto.gov.br/ccivil_03/_ato2011-

2014/2014/lei/112965.htm> Acesso em: 19 de out. 2016.

[6] Brasil. Lei 13.146. Institui a Lei Brasileira de Inclusão da Pessoa com Deficiência (Estatuto da Pessoa com Deficiência), de 06 de julho de 2015. Brasília, DF, 2015. Disponível em :

$<$ http://www.planalto.gov.br/ccivil 03/ ato20152018/2015/lei/113146.htm>. Acesso em: 19 de out. 2016.

[7] Capra, E. P., Leal Ferreira, S. B., Silveira, D. S., Modesto, D. M. 2012. Desafio Nacional: o Acesso à Web pelos Analfabetos Funcionais. In: Encontro da Associação Nacional de Pós-Graduação e Pesquisa em Administração, 2012, Rio de Janeiro. XXXVI ENANPAD.

[8] CETIC.br. Centro Regional de Estudos para o Desenvolvimento da Sociedade da Informação sob os Auspícios da UNESCO - C6 - Proporção de Usuários de Internet, por Atividades Realizadas na Internet - Busca de Informação, CGI.br, 2015. Disponível em: $<$ http://cetic.br/tics/usuarios/2015/total-brasil/C6/> Acesso em: 19 de out. 2016.

[9] Coh-Metrix-Dementia. 2016. Disponível em: $<$ http://143.107.183.175:22380> Acesso em: 20 de out. 2016.

[10] Cunha, A. L. V. 2015. Coh-Metrix-Dementia: Análise Automática de Distúrbios de Linguagem nas Demências Utilizando Processamento de Línguas Naturais. Dissertação (Mestrado), Universidade de São Paulo, Instituto de Ciências Matemáticas e de Computação, São Paulo.

[11] IBGE. 2016. Instituto Brasileiro de Geografia e Estatística. Disponível em: < http://www.ibge.gov.br/home>. Acesso em: 22 de out. 2016.

[12] INAF. 2015. Indicador de Alfabetismo Funcional. Disponível em: $<$ http://www.ipm.org.br/ptbr/programas/inaf/relatoriosinafbrasil/Paginas/Inaf-2015--Alfabetismo-no-Mundo-do-Trabalho.aspx.> Acesso em: 20 de out. 2016.

[13] Kodagoda, N., Wong, B. 2008. Effects of Low \& High Literacy on User Performance in Information Search and Retrieval. In: Proceedings of the 22nd British HCI Group Annual Conference on People and Computers: Culture, Creativity, Interaction, pp.173-181. The British Computer Society, Swinton, UK.

[14] Leffa, V. J. 1996. Fatores da compreensão na leitura. Cadernos do IL, Porto Alegre, v. 5, n. 15, p.143-159. Disponível em: $<$ http://www.leffa.pro.br/textos/trabalhos/fatores.pdf $>$. Acesso em: 20 de out. 2016.
[15] McCarthy, P. M., Lewis, G. A., Dufty, D. F., \& McNamara, D. S. 2006. Analyzing writing styles with Coh-Metrix. In G. C. J.Sutcliffe and R. G.Goebel (Eds.), Proceedings of the Florida Artificial Intelligence Research Society International Conference (FLAIRS) (pp. 764-770). Menlo Park, CA: AAAI Press.

[16] Melo, A., Piccolo, L., Ávila, I., Tambascia, C. 2008, Usabilidade, Acessibilidade e Inteligibilidade Aplicadas em Interfaces para Analfabetos, Idosos e Pessoas com Deficiência. In: VIII Brazilian Symposium on Human Factors in Computing Systems, 2008, Porto Alegre - RS.

[17] Nazário, D., da Silva, P. Rover, A. 2012. Avaliação da Qualidade da Informação Disponibilizada no Portal da Transparência do Governo Federal. Revista Democracia Digital e Governo Eletrônico (ISSN 2175-9391), n 6, p. 180-199.

[18] Teixeira, P. L. F., Souza, M. G., Farias, M. A. 2012. O Analfabetismo Funcional em Alunos Universitários. In: VII Congresso Norte e Nordeste em Pesquisa e Inovação. Palmas, TO.

[19] IBGE. Pesquisa Nacional de Amostra por Domicílios. 2015. Disponível em :

$<$ http://www.ibge.gov.br/home/estatistica/populacao/trabalho erendimento/pnad2015/default_sintese.shtm> Acesso em: 22 out. 2016.

[20] Scarton, C., Almeida, D., Aluísio, S. 2007. Análise da Inteligibilidade de textos via ferramentas de Processamento de Língua Natural: adaptando as métricas do Coh-Metrix para o Português. In: Proceedings of the $7^{\circ}$ Brazilian Symposium in Information and Human Language Technology, São Carlos, São Paulo.

[21] Scarton, C.; Aluísio, S. 2010. Análise da Inteligibilidade de textos via ferramentas de Processamento de Língua Natural: adaptando as métricas do Coh-Metrix para o Português. Revista Linguamática, vol. 2, no 1, p.45-62. ISSN: 16470818, abr, 2010.

[22] SPS. Secretaria da Previdência Social. Disponível em: $<\mathrm{http}$ ://www.previdencia.gov.br>. Acesso em: 19 out. 2016.

[23] SPS - Acessibilidade. Acessibilidade do Portal da Secretaria da Previdência Social. Disponível em: $<$ http://www.previdencia.gov.br/acessibilidade/>. Acesso em: 22 de out. 2016. 